\title{
Redox cycling induces spermptosis and necrosis in stallion spermatozoa while the hydroxyl radical $(\mathrm{OH} \cdot)$ only induces spermptosis
}

P. Martin Munoz, L. Anel-Lopez, J. M. Ortiz-Rodriguez, M. Alvarez, P. de Paz, C. Balao da Silva, Heriberto Rodriguez-Martinez, M. C. Gil, L. Anel, F. J. Pena and C. Ortega Ferrusola

The self-archived postprint version of this journal article is available at Linköping University Institutional Repository (DiVA):

http://urn.kb.se/resolve?urn=urn:nbn:se:liu:diva-144548

N.B.: When citing this work, cite the original publication.

Munoz, P. M., Anel-Lopez, L., Ortiz-Rodriguez, J. M., Alvarez, M., de Paz, P., Balao da Silva, C., Rodriguez-Martinez, H., Gil, M. C., Anel, L., Pena, F. J., Ortega Ferrusola, C., (2018), Redox cycling induces spermptosis and necrosis in stallion spermatozoa while the hydroxyl radical (OH center dot) only induces spermptosis, Reproduction in domestic animals, 53(1), 54-67.

https://doi.org/10.1111/rda.13052

Original publication available at:

https://doi.org/10.1111/rda.13052

Copyright: Wiley (12 months)

http://eu.wiley.com/WileyCDA/ 


\section{Redox cycling and the Hydroxyl radical (OH॰) induce spermptosis in stallion spermatozoa.}

${ }^{1}$ Martin Muñoz P, ${ }^{4}$ Ortega Ferrusola C, ${ }^{4}$ Anel-López L, ${ }^{1}$ Ortiz- Rodriguez JM, ${ }^{4}$ Alvarez M, ${ }^{5}$ de Paz P, ${ }^{6}$ Balao da Silva C, ${ }^{2}$ Rodriguez Martinez H, ${ }^{1}$ Gil MC, ${ }^{4}$ Anel L, ${ }^{1}$ Peña FJ*

${ }^{1}$ Laboratory of Equine Reproduction and Equine Spermatology, Veterinary Teaching Hospital, University of Extremadura, Cáceres, Spain. ${ }^{2}$ Department of Clinical and Experimental Medicine, Faculty of Medicine \& Health Sciences, Linköping University, Linköping, Sweden; ${ }^{4}$ Reproduction and Obstetrics Department of Animal Medicine and Surgery, University of León, Spain.

${ }^{5}$ Department of Molecular Biology, University of León, Spain

${ }^{6}$ Portalagre Polytechnic Institute, Superior Agriculture School of Elvas, Portugal

*Correspondence to Dr. FJ Peña, Veterinary Teaching Hospital, Laboratory of Equine Spermatology and Reproduction, Faculty of Veterinary Medicine University of Extremadura Avd de la Universidad s/n 10003 Cáceres Spain. E-mail fjuanpvega@unex.es

phone +34 927-257167

fax +34927257102

\section{Acknowledgements}

The authors received financial support for this study from the Ministerio de Economía y Competitividad-FEDER, Madrid, Spain, grant AGL2013-43211-R, Junta de Extremadura-FEDER (GR 15029) and the Swedish Research Councils VR (521-20116353) and Formas (221-2011-512). PMM is supported by a pre-doctoral grant from the Ministerio de Educación, Cultura y Deporte, Madrid Spain FPU13/03991. COF is supported by a post-doctoral grant from the Ministerio de Economía y Competitividad “Juan de la Cierva” IJCI-2014-21671. 


\begin{abstract}
Oxidative stress is considered a major factor explaining sperm dysfunction of spermatozoa surviving freezing and thawing, and also is considered in the basis of a special form of apoptosis in cryopreserved spermatozoa visible after thawing. However, studies directly linking oxidative stress independently of other factors occurring during cryopreservation are scarce. In order to provide a direct link between oxidative stress and induction of apoptotic changes, stallion spermatozoa were induced to oxidative stress through redox cycling by exposure to 2 methyl-1,4-naftoquinone (menadione), or induction of hydroxyl radical formation by $\mathrm{FeSO}_{4}$ exposure. Either exposure induced significant increases $(\mathrm{p}<0-05)$ in two markers of oxidative stress; 8-iso- $\mathrm{PGF}_{2 \alpha}$ and 4hydroxynonenal (4-HNE). While both treatments induced changes indicative of spermptosis (caspase 3 activation and decrease in mitochondrial membrane potential) $(\mathrm{p}<0.01)$, menadione induced a dramatic drop in motility and thiol content in stallion spermatozoa. We provide thus evidence that oxidative stress is behind spermptosis, and that thiol content is a key factor for stallion sperm function.
\end{abstract}

Key words: menadione, ROS, sperm senescence, equine

\title{
INTRODUCTION
}

Oxidative stress is becoming an area of increasing interest in spermatology[1]. Equine spermatozoa behave noteworthy in this specific area owing to their especially intense oxidative phosphorylation in the mitochondria [2,3]. While the effects of oxidative stress are well know and recognized as a major constrain reducing the efficiency of many sperm biotechnologies, the intrinsic mechanisms leading to cell damage are largely ignored. The concept of oxidative stress is under current revision, and reactive oxygen species (ROS) are no longer considered as unregulated molecules having only damaging effects on spermatozoa[4]. On the contrary, tight regulation of the production and scavenging of ROS regulates important sperm functions including capacitation and motility[5]. When discussing the damaging effects of ROS, one important aspect is the oxidant species considered[6]. While superoxide $\left(\mathrm{O}_{2}^{-}\right)$and hydrogen peroxide $\left(\mathrm{H}_{2} \mathrm{O}_{2}\right)$ are important signaling molecules, the hydroxyl radical $(\mathrm{OH})$ is considered as highly harmful and with few regulatory functions, if any. In stallion spermatozoa, the main sources of ROS are the mitochondria, whose dysfunction represents a major cause of ROS imbalance leading to compromised sperm function[3]. Ccryopreservation induces dead of spermatozoa due to osmotic imbalance at thawing, causing mechanic rupture of the membrane. As well, cryopreservation causes premature senescence of the surviving spermatozoa due to oxidative stress caused by mitochondrial malfunction[7, 8]. This particular form of senescence in cryopreserved spermatozoa has been termed spermptosis $[9,10]$. However, our knowledge in this particular area is still scarce, and detailed mechanisms involved in the regulation the fragile redox homeostasis in spermatozoa are largely unknown. On the other hand, representing an apparent paradox, fertile stallion spermatozoa produce more ROS[11, 12], due to increased oxidative phosphorylation in the mitochondria, compared to less-fertile spermatozoa. Menadione (2-methyl 1, 4-naphtoquinone) is an oxidant able to induce apoptosis in somatic cells inducing opening of the mitochondrial pore and the release of cytochrome C[13-15]. On the other hand, the Hydroxyl radical $(\mathrm{OH})$ is considered as a major inducer of oxidative damage due to its high ability to react with lipids, proteins and DNA bases $[16,17]$. In order to increase our knowledge of mechanisms leading to oxidative stress, stallion spermatozoa were exposed to menadione 
and $\mathrm{FeSO}_{4}$ to induce oxidative stress through different mechanisms. The hypothesis tested was that these differ in their ability to damage stallion spermatozoa, hoping that a better knowledge of these mechanisms may help to develop better strategies of sperm conservation.

\section{MATERIAL AND METHODS}

\section{Reagents and media}

Live dead aqua [(Ex: 405 nm, Em: 525 nm), (Ref: L34957)], Hoechst 33342 [(Excitation: 350 nm, Emission: 461 nm) (Ref: H3570)], ThiolTracker Violet [(Ex: 404 nm, Em: 526 nm), (Ref: T10095)], Mitotracker Deep Red [(Ex 644 nm Em 655nm) (Ref M22426)] Cell Event Caspase-3/7 Green Detection Reagent (Excitation, 502 nm; Emission: 530 nm) (Ref: C10423); ethidium homodimer [(Excitation, 528 nm; Emission, $617 \mathrm{~nm}$ ) (Ref: E1169)] and LIVE/DEAD Fixable Far Red Dead Cell Solution [(Ex: 633 nm, Em: 655 nm), (Ref: L10120)] were purchased from Molecular Probes (Leiden, The Netherlands). Anti-4 hydroxynonenal (4-HNE) antibody [HNEJ-2] (Ref: ab48506), goat anti-mouse IgG H\&L (Alexa Fluor® 647) [(Ex: 652 nm, Em: 668 nm), (Ref: ab150115)], Anti 8-IsoProstglandin F2 $\alpha$ antibody (Ref: ab2280), and Goat Anti-Rabbit IgG H\&L antibody (Alexa Fluor ${ }^{\circledR}$ 405) (Ex 405, Em 488) were purchased from Abcam (Cambridge, UK). Menadione and all other chemicals were purchased from Sigma Aldrich (Madrid, Spain).

\section{Semen collection and processing}

Semen was obtained from seven Pure Spanish horses (PRE) (three ejaculates each) individually housed at the Veterinary Teaching Hospital of the University of Extremadura, Cáceres, Spain. Stallions were maintained according to institutional and European regulations for animal welfare. Ejaculates were collected on a regular basis (two collections/week) during the 2016 breeding season using a pre-warmed, lubricated Missouri model artificial vagina with an inline filter to eliminate the gel fraction. The semen samples were immediately transported to the laboratory for evaluation and processing. The ejaculate samples were extended 1:1 in INRA-96, centrifuged (600 g x $10 \mathrm{~min}$ ), and re-suspended in Biggers-Whitten-Whittingham (BWW) medium[2] supplemented with $1 \%$ PVA to obtain a concentration of $50 \times 10^{6}$ spermatozoa $/ \mathrm{mL}$. All experiments followed a split-sample design with every ejaculate divided between control and treatment groups. All experiments were repeated using three different ejaculates from each of the seven stallions (21 replicates in total).

\section{Induction of oxidative stress}

To induce an oxidative insult, semen samples were incubated in presence of $\mathrm{FeSO}_{4}$ $(800 \mu \mathrm{M})$ or menadinone $(200 \mu \mathrm{M})$.

\section{Sperm motility}

Sperm motility and kinematic parameters were assessed using a Computer Assisted Sperm Analysis (CASA) system (ISAS Proiser, Valencia, Spain). Semen was loaded in a Leja ${ }^{\circledR}$ chamber with $20 \mu \mathrm{m}$ of depth (Leja, Amsterdam, The Netherlands) and placed on a warmed stage at $38^{\circ} \mathrm{C}$. The analysis was based on an evaluation of 60 consecutive digitalized images obtained using a 10x negative phase-contrast objective (Olympus CX 
41). At least three different fields were recorded to ensure that at least 200 spermatozoa were analyzed per sample. Spermatozoa with a VAP (average velocity) $<15 \mu \mathrm{m} / \mathrm{s}$ were considered immotile, while spermatozoa with a VAP > $35 \mu \mathrm{m} / \mathrm{s}$ were considered motile. Spermatozoa deviating $<45 \%$ from a straight line were catalogued as linearly motile.

\section{Simultaneous determination of live and dead spermatozoa, high and low mitochondrial membrane potential and 8-iso prostaglandin F2 $\alpha$}

The live dead Fixable dead cell stain, aqua fluorescent reactive dye (Ex 367/Em 451) can be excited with the $404 \mathrm{~nm}$ laser emitting at $450 \mathrm{~nm}$. This assay is based on the reaction of a fluorescent reactive dye with cellular amines. The reactive dye can permeate the compromised membranes of necrotic cells and react with free amines both in the interior of the cell and on the cell surface resulting in intense fluorescent staining. In contrast, only cell surface amines of live cells are available to react with the dye resulting in dim staining. Cells $\left(1-5 \times 10^{6}\right)$ were stained with $1 \mu \mathrm{L}$ of dye and $0,3 \mu \mathrm{L}$ of Mitotracker deep red stock solution and incubated in the dark at room temperature. The spermatozoa ( $1 \mathrm{x}$ $10^{6} / \mathrm{mL}$ ) then were washed with saline-HEPES medium and fixed in $2 \%$ paraformaldehyde in phosphate-buffered saline (PBS) at room temperature (RT) for 15 minutes. After fixation, the cells were washed twice with PBS and incubated in the same buffer with $2 \mu \mathrm{L} / \mathrm{ml}$ of a solution containing $0.1 \mathrm{mg} / \mathrm{mL}$ of Anti 8-iso-Prostaglandin $\mathrm{F}_{2 \alpha}$ primary antibody and incubated in the dark RT, for 30 minutes. Then samples were washed in PBS and the secondary antibody $(2 \mu \mathrm{L} / \mathrm{ml})$ added (Antirrabit Alexa Fluor 402) and further incubated in the dark, RT for $30 \mathrm{~min}$. Samples were then washed again in PBS and run in the flow cytometer. Positive controls consisted in $\mathrm{F}_{2+}$ and menadione treated sperm to induce oxidative stress, and fluorescence minus one (FMO) controls were used to determine antibody positivity. Unstained and single stained controls were used to set compensations. Representative cytograms of the assay are depicted in figure 1.

\section{Simultaneous determination of live and dead cells, caspase 3 and 7 activity and lipid peroxidation (4-HNE positive cells)}

CellEvent ${ }^{\mathrm{TM}}$ Caspase-3/7 Green Detection Reagent is a fluorogenic substrate for activated caspases 3 and 7. The reagent consists of a four-amino-acid peptide (DEVD) conjugated to a nucleic acid-binding dye. This cell-permeant substrate is intrinsically non-fluorescent because the DEVD peptide inhibits the ability of the dye to bind to DNA. After activation of caspase- 3 and caspase-7 in apoptotic cells, the DEVD peptide is cleaved, enabling the dye to bind to DNA and to produce a bright, fluorogenic response with absorption/emission maxima of $\sim 502 / 530 \mathrm{~nm}$. One important advantage of this assay is that no washing steps are required, minimizing cell losses. Stock solutions of CellEvent (2 mM in DMSO), ethidium homodimer (1.167 mM in DMSO), and Hoechst 33342 (1.62 $\mathrm{mM}$ in water) were prepared. Spermatozoa $\left(5 \times 10^{6} / \mathrm{mL}\right)$ in $1 \mathrm{~mL}$ of PBS were stained with $2 \mu \mathrm{L} / \mathrm{ml}$ of a stock solution of $0.1 \mathrm{mg} / \mathrm{ML}$ of anti 4-HNE primary antibody and incubated at RT in the dark for 30min; the cells were washed with PBS and $2 \mu \mathrm{L} / \mathrm{ml}$ of secondary Anti mouse Alexa Fluor 647 and $1 \mu \mathrm{L}$ of CellEvent, $0.3 \mu \mathrm{L}$ of Hoechst 33342 and further incubated in the dark, atRT for additional $30 \mathrm{~min}$. Cells were then washed in PBS, followed by addition of $0.3 \mu \mathrm{L}$ of ethidium homodimer. After incubation for five minutes, samples were immediately run on the flow cytometer. Representative cytograms of the assay are shown in Figure 2.

Simultaneous identification of live and dead cells, and intracellularly free thiols 
Live/Dead fixable far red dead cell stain was used to monitor live and dead sperm while the Thiol tracker violet reagent was used to monitor free intracellular thiols. Thiol tracker stock solution was prepared in DMSO (20 mM) and sperm (1-5x106 sperm in $1 \mathrm{ml})$ were stained with $1 \mu \mathrm{L}$ of Thiol tracker, $1 \mu \mathrm{l}$ of of Live death far red stain and $1 \mu \mathrm{L}$ of CellEvent and incubated in the dark for 30 minutes, before flow cytometric reading.

\section{Flow cytometry}

Analyses were done using a MACSQuant Analyser 10 (Miltenyi Biotech) flow cytometer equipped with three lasers; emitting at $405 \mathrm{~nm}, 488 \mathrm{~nm}$, and $635 \mathrm{~nm}$ and 10 photomultiplier tubes (PMTs) (V1: excitation $405 \mathrm{~nm}$, emission 450/50 nm, V2: excitation $405 \mathrm{~nm}$, emission 525/50 nm, B1: excitation $488 \mathrm{~nm}$, emission 525/50 nm, B2: excitation $488 \mathrm{~nm}$, emission 585/40 nm, B3: excitation $488 \mathrm{~nm}$, emission 655-730 nm (655LP + split 730), B4: excitation 499 nm, emission 750 LP, R1: excitation 635 nm, emission 655-730 nm (655LP+split 730) and R2: excitation $635 \mathrm{~nm}$, emission filter 750 LP). The system was controlled using MACSQuantify software. Sperm subpopulations were divided by quadrants to quantify their individual frequency. Forward- and sideways light scatters were recorded for a total of 50,000 events per sample. Non-sperm events were eliminated by gating the sperm population after Hoechst 33342 staining or Mitotracker deep red staining. The instrument was calibrated daily using specific calibration beads provided by the manufacturer. Proper compensation overlap was performed before each particular experiment.

\section{Statistical analysis}

All experiments were repeated at least three times with independent samples (three independent ejaculates from each of the seven stallions), and the results were analyzed by ANOVA using SPSS 19.0 software for Mac. $\mathrm{P}<0.05$ was regarded as significant.

\section{RESULTS}

\section{Induction of oxidative stress in stallion spermatozoa}

Oxidative stress was provoked following two methods, inducing redox cycling with menadione [14], and through the induction of the Fenton reaction[18-22]. Responses were monitored using two well-established markers of oxidative stress, 4- hydroxinonenal [2327] and 8-iso-PGF $2 \alpha$ [28-31]. Both systems induced oxidative stress in stallion spermatozoa, with significant increases in both markers. The 8-iso- $\mathrm{PGF}_{2 \alpha}$ increased specially after the induction of the Fenton reaction, although after 6 hours of incubation menadione also induced significant increases in this adduct (fig 3 A-D). The presence of 4-HNE followed a similar trend (fig 4), being the increases in this marker more intense after the induction of the Fenton reaction, with the exception of the percentage of cells positive both for 4-HNE and caspase 3 that was more intense after 6 hours of incubation, when menadione was present (fig $4 \mathrm{~d}$ )

Induction of the Fenton reaction impairs sperm motility while menadione suppresses motility 
Induction of the Fenton reaction resulted in significant of reductions of sperm motility (fig 5) $(\mathrm{p}<0.01)$. Both total and linear motile motilities were affected at all incubation times considered. On the other hand, menadione induced cessation of the sperm movement, already after 1 hour of incubation $(\mathrm{p}<0.01)$ and abolished progressive motility $(\mathrm{p}<0.001)$ (fig 5).

\section{Oxidative stress reduces sperm viability and activates caspase 3}

Both methods of induction of oxidative stress reduced stallion sperm viability, this effect was evident after 1 hour of incubation (Fig 6), which further reduced the percentage of live spermatozoa after 6 hours of incubation. At this time point, almost all spermatozoa exposed to oxidative stress were dead, while controls still had $20 \%$ of live spermatozoa (fig 6 D). To determine whether this mortality was related to spermptosis, caspase 3 was simultaneously measured. After 2 hour of incubation both methods increased caspase 3 activity (fig 7). Ethidium homodimer uptake was used to determine the importance of necrosis in this model of sperm death, (fig 8). After 6 and 9 hours of incubation, menadione induced necrotic sperm death (fig $8 \mathrm{C}$ and $\mathrm{D}$ ).

\section{Oxidative stress decreases mitochondrial membrane potential ( $\Psi \varphi m)$}

Menadione and $\mathrm{SO}_{4} \mathrm{Fe}$ caused significant and time-dependent decreases in mitochondrial membrane potential, reaching a maximum decrease after 9 hours of incubation at $37^{\circ} \mathrm{C}$ (fig 9). After 6 hours of incubation, the drop in $\Psi \varphi$ m was significantly higher in $\mathrm{SO}_{4} \mathrm{Fe}-$ treated samples $(\mathrm{p}<0.01)$ (fig $9 \mathrm{C})$.

\section{Depletion of intra-cellular thiols after induction of oxidative stress}

Induction of redox cycling with menadione caused a rapid and nearly complete depletion of total thiol content in stallion spermatozoa (fig 10) $(\mathrm{p}<0.001)$. Thiol concentrations were minimal after 1 hour of incubation thiols, and undetected past three hours. On the contrary, induction of the Fenton reaction reduced but not depleted thiol content of stallion spermatozoa after three hours of incubation (fig $10 \mathrm{~b}-\mathrm{d}$ ).

\section{DISCUSSION}

In an attempt to improve our knowledge of oxidative stress in the equine male gamete, we investigated how two methods of induction of oxidative stress could lead to differential effects on sperm functionality. Although oxidative stress is admitted as a major damaging factor in spermatozoa, the direct effect of different mechanisms of induction of oxidative stress has not been sufficiently studied with only one report in human spermatozoa [32]. Both methods induced significant changes in spermatozoa attributable to oxidative stress, including reduction or loss of sperm motility and reduced viability with activation of caspase 3 and reduction of mitochondrial membrane potential. However, differences between methods of induction of oxidative stress also occurred.

Both methods induced oxidative stress as indicated by increases in 8-iso-PGF $2 \alpha$ and or 4HNE. However, they yield differential responses. Menadione abolished sperm motility, while induction of the Fenton reaction only reduced sperm movement. In order to determine the potential mechanisms behind these differences, the total intracellular thiol content was determined, and the ability of both methods to increase 4-HNE monitored. 
Previous studies show that the total thiol content of an spermatozoon relates to cell functionality, especially phenotypic motility [33, 34]. On the other hand, increased levels of 4-HNE are linked to lipid peroxidation and oxidative stress in spermatozoa [35-37]. We also evaluated the utility of 8-iso-PGF $2 \alpha$ as marker of oxidative stress in spermatozoa. Isoprostanes are prostaglandin isomers produced from the peroxidation of polyunsaturated fatty acids from the cellular membrane. They have been used as a specific index of cellular lipoperoxidation and as an indirect measure of oxidative stress[38]. This compound has recently been identified in stallion spermatozoa[33]. Treatment with $\mathrm{SO}_{4} \mathrm{Fe}$ to induce the Fenton reaction was more effective increasing this marker. Yet, despite of increases in this marker, detrimental effects of $\mathrm{SO}_{4} \mathrm{Fe}$ were not as intense as the ones induced by menanione. Also worth a commentary the fact that 8-iso-PGF $2 \alpha$ appeared increased in live spermatozoa after exposition to $\mathrm{SO}_{4} \mathrm{Fe}$, but only increased after 6 hours of incubation in dead spermatozoa after exposition to menadione. Exposition of stallion spermatozoa to $\mathrm{SO}_{4} \mathrm{Fe}$ also was more efficacious inducing the formation of 4HNE, especially among those caspase 3 positive-spermatozoa, with exception of samples incubated up to 9 hours in where no differences were observed respect to controls, and where only menadione increased 4-HNE.

These facts can be explained based in different mechanisms behind the effects of both compounds; $\mathrm{SO}_{4} \mathrm{Fe}$ induces the formation of the $\mathrm{HO}^{\bullet}$ radical, menadione induces redox cycling[32, 39] increasing the production of $\mathrm{H}_{2} \mathrm{O}_{2}$; apparently redox cycling representing a major disrupting factor of the redox homeostasis as evidenced by the rapid and intense depletion of thiols after menadione treatment. However, both methods were able to induce caspase activation; thus supporting the concept that redox deregulation activates an apoptotic mechanism in equine spermatozoa[40-42]. This mechanism has been linked to lipid peroxidation and the formation of 4-HNE[34, 43]. Treatment with $\mathrm{SO}_{4} \mathrm{Fe}$ induced more formation of 4-HNE, especially in the population of caspase 3 positive spermatozoa, with menadione only inducing more formation after 9 hours of incubation. However, menadione was more efficacious inducing caspase 3 activation, most likely owing to the ability of menadione to open the mitochondrial transition pore [15, 44], as previously demonstrated to ocurr during cryopreservation[45]. A reduced mitochondrial membrane potential observed after menadione treatment supports this reasoning. Menadione also rapidly depleted thiol content in sperm. Depletion of GSH is considered an early event of apoptosis [46] with important regulatory functions of the process of programed cell death, so increased caspase 3 activity after menadione treatment in stallion spermatozoa can well be explained by depletion of sperm GSH. Previous findings from our laboratory, linking GSH depletion and increased caspase 3 after cryopreservation, also support this hypothesis[34]. Menadione also induced necrotic cell death after 1 hour of incubation, while $\mathrm{SO}_{4} \mathrm{Fe}$ exposition needed 9 hours of incubation to induce necrotic cell death. The more dramatic changes were the effects of menadione on sperm motility and the intense depletion of thiols after exposure to menadione. These findings suggest, as previously indicated[34], that thiol sperm content is critical for sperm function, motility in particular. Menadione, as other quinones, can undergo one-electron reduction by $\mathrm{NAD}(\mathrm{P}) \mathrm{H}-$ dependent reductases resulting in the generation of semi-quinone radicals, which reduces molecular oxygen, producing ROS such as superoxide anion, and leading to redoxcycling reactions. Quinones are detoxified by quinone-reductases in the two-electron reduction to redox-stable hydroquinones. Also as electrophiles, quinones can form Sadducts with cellular thiols, which involves a 1,4-reductive Michael-type addition which is referred to also as thiol-(S)-alkylation [47, 48]. Menadione can thus act either through redox cycling and through alkylation of thiols of critical proteins for sperm function[49]. 
The latter provides a plausible explanation for the rapid effect on sperm motility. Menadione in hepatocytes is associated with depletion of GSH, and concomitant increases in oxidized glutathione disulfide (GSSG) $[50,51]$ suggesting that oxidation of GSH to GSSGaccounted for $75 \%$ of the total GSH loss; but about $15 \%$ of the cellular GSH reacted directly with menadione to produce a GSH-menadione conjugate[51]. A similar picture may be ocurring in stallion spermatozoa.

In summary, we have provided evidence linking oxidative stress and changes resembling apoptosis in stallion spermatozoa, as are decreased mitochondrial membrane potential and caspase 3 activation, the latter linked to increased 4-HNE. Moreover, thiols seem to play a major role in sperm function and in defense against oxidative stress.

\section{REFERENCES}

[1] da Silva, C. M.; Macias-Garcia, B.; Miro-Moran, A.; Gonzalez-Fernandez, L.; Morillo-Rodriguez, A.; Ortega-Ferrusola, C.; Gallardo-Bolanos, J. M.; Stilwell, G.; Tapia, J. A.; Pena, F. J. Melatonin reduces lipid peroxidation and apoptotic-like changes in stallion spermatozoa. J Pineal Res 51:172-179; 2011.

[2] Davila, M. P.; Munoz, P. M.; Bolanos, J. M.; Stout, T. A.; Gadella, B. M.; Tapia, J. A.; da Silva, C. B.; Ferrusola, C. O.; Pena, F. J. Mitochondrial ATP is required for the maintenance of membrane integrity in stallion spermatozoa, whereas motility requires both glycolysis and oxidative phosphorylation. Reproduction 152:683-694; 2016.

[3] Plaza Davila, M.; Martin Munoz, P.; Tapia, J. A.; Ortega Ferrusola, C.; Balao da Silva, C. C.; Pena, F. J. Inhibition of Mitochondrial Complex I Leads to Decreased Motility and Membrane Integrity Related to Increased Hydrogen Peroxide and Reduced ATP Production, while the Inhibition of Glycolysis Has Less Impact on Sperm Motility. PLoS One 10:e0138777; 2015.

[4] Holmstrom, K. M.; Finkel, T. Cellular mechanisms and physiological consequences of redox-dependent signalling. Nat Rev Mol Cell Biol 15:411-421; 2014.

[5] Freitas, M., Vijayaraghavan S, Fardilha M Signalling mechanisms in mammalian sperm motility Biology of Reproduction 96:2-12; 2017.

[6] Kalyanaraman, B. Teaching the basics of redox biology to medical and graduate students: Oxidants, antioxidants and disease mechanisms. Redox Biol 1:244-257; 2013.

[7] Pena, F. J.; Plaza Davila, M.; Ball, B. A.; Squires, E. L.; Martin Munoz, P.; Ortega Ferrusola, C.; Balao da Silva, C. The Impact of Reproductive Technologies on Stallion Mitochondrial Function. Reprod Domest Anim 50:529-537; 2015.

[8] Pena, F. J.; Garcia, B. M.; Samper, J. C.; Aparicio, I. M.; Tapia, J. A.; Ferrusola, C. O. Dissecting the molecular damage to stallion spermatozoa: the way to improve current cryopreservation protocols? Theriogenology 76:1177-1186; 2011.

[9] Ortega-Ferrusola, C.; Anel-Lopez, L.; Martin-Munoz, P.; Ortiz-Rodriguez, J. M.; Gil, M. C.; Alvarez, M.; de Paz, P.; Ezquerra, L. J.; Masot, A. J.; Redondo, E.; Anel, L.; Pena, F. J. Computational flow cytometry reveals that cryopreservation induces spermptosis but subpopulations of spermatozoa may experience capacitationlike changes. Reproduction 153:293-304; 2017.

[10] Gallardo Bolanos, J. M.; Balao da Silva, C. M.; Martin Munoz, P.; Morillo Rodriguez, A.; Plaza Davila, M.; Rodriguez-Martinez, H.; Aparicio, I. M.; Tapia, J. A.; Ortega Ferrusola, C.; Pena, F. J. Phosphorylated AKT preserves stallion sperm viability and motility by inhibiting caspases 3 and 7. Reproduction 148:221-235; 2014. 
[11] Gibb, Z.; Lambourne, S. R.; Aitken, R. J. The paradoxical relationship between stallion fertility and oxidative stress. Biol Reprod 91:77; 2014.

[12] Yeste, M.; Estrada, E.; Rocha, L. G.; Marin, H.; Rodriguez-Gil, J. E.; Miro, J. Cryotolerance of stallion spermatozoa is related to ROS production and mitochondrial membrane potential rather than to the integrity of sperm nucleus. Andrology 3:395-407; 2015.

[13] Kim, Y. J.; Shin, Y. K.; Sohn, D. S.; Lee, C. S. Menadione induces the formation of reactive oxygen species and depletion of GSH-mediated apoptosis and inhibits the FAK-mediated cell invasion. Naunyn Schmiedebergs Arch Pharmacol 387:799-809; 2014.

[14] Loor, G.; Kondapalli, J.; Schriewer, J. M.; Chandel, N. S.; Vanden Hoek, T. L.; Schumacker, P. T. Menadione triggers cell death through ROS-dependent mechanisms involving PARP activation without requiring apoptosis. Free Radic Biol Med 49:19251936; 2010.

[15] Gerasimenko, J. V.; Gerasimenko, O. V.; Palejwala, A.; Tepikin, A. V.;

Petersen, O. H.; Watson, A. J. Menadione-induced apoptosis: roles of cytosolic $\mathrm{Ca}(2+)$ elevations and the mitochondrial permeability transition pore. J Cell Sci 115:485-497; 2002.

[16] Aitken, R. J.; Harkiss, D.; Buckingham, D. W. Analysis of lipid peroxidation mechanisms in human spermatozoa. Mol Reprod Dev 35:302-315; 1993.

[17] Aitken, R. J.; Harkiss, D.; Buckingham, D. Relationship between iron-catalysed lipid peroxidation potential and human sperm function. J Reprod Fertil 98:257-265; 1993.

[18] Burkitt, M. J.; Gilbert, B. C. Model studies of the iron-catalysed Haber-Weiss cycle and the ascorbate-driven Fenton reaction. Free Radic Res Commun 10:265-280; 1990.

[19] Imlay, J. A.; Chin, S. M.; Linn, S. Toxic DNA damage by hydrogen peroxide through the Fenton reaction in vivo and in vitro. Science 240:640-642; 1988.

[20] Zsupan, I.; Hadhazy, C.; Nagy, V.; Jeney, F.; Nagy, I. The effect of OH(.) radicals generated by Fenton reaction on the growth and cartilage differentiation in limb bud cell culture. J Submicrosc Cytol 19:445-454; 1987.

[21] Sestili, P.; Piedimonte, G.; Cattabeni, F.; Cantoni, O. Induction of DNA breakage and suppression of DNA synthesis by the $\mathrm{OH}$ radical generated in a Fentonlike reaction. Biochem Int 12:493-501; 1986.

[22] Bilinski, T.; Krawiec, Z.; Liczmanski, A.; Litwinska, J. Is hydroxyl radical generated by the Fenton reaction in vivo? Biochem Biophys Res Commun 130:533-539; 1985.

[23] Laggner, H.; Gmeiner, B. M. Investigating the role of $\mathrm{H}(2) \mathrm{S}$ in 4-HNE scavenging. Methods Enzymol 555:3-18; 2015.

[24] Kashyap, M. P.; Singh, A. K.; Yadav, D. K.; Siddiqui, M. A.; Srivastava, R. K.; Chaturvedi, V.; Rai, N. 4-Hydroxy-trans-2-nonenal (4-HNE) induces neuronal SHSY5Y cell death via hampering ATP binding at kinase domain of Akt1. Arch Toxicol 89:243-258; 2015.

[25] Lee, W. C.; Wong, H. Y.; Chai, Y. Y.; Shi, C. W.; Amino, N.; Kikuchi, S.; Huang, S. H. Lipid peroxidation dysregulation in ischemic stroke: plasma 4-HNE as a potential biomarker? Biochem Biophys Res Commun 425:842-847; 2012.

[26] Foucaud, L.; Goulaouic, S.; Bennasroune, A.; Laval-Gilly, P.; Brown, D.; Stone, V.; Falla, J. Oxidative stress induction by nanoparticles in THP-1 cells with 4-HNE production: stress biomarker or oxidative stress signalling molecule? Toxicol In Vitro 24:1512-1520; 2010. 
[27] Majima, H. J.; Nakanishi-Ueda, T.; Ozawa, T. 4-hydroxy-2-nonenal (4-HNE) staining by anti-HNE antibody. Methods Mol Biol 196:31-34; 2002.

[28] Xiao, Y.; Fu, X.; Pattengale, P.; Dien Bard, J.; Xu, Y. K.; O'Gorman, M. R. A sensitive LC-MS/MS method for the quantification of urinary 8-iso-prostaglandin F2alpha (8-iso-PGF2alpha) including pediatric reference interval. Clin Chim Acta 460:128-134; 2016.

[29] Li, S.; Hao, H.; Zhou, P.; Gao, P. M.; Xiao, X. Blood and urine 8-iso-PGF2alpha levels in babies of different gestational ages. Int J Clin Exp Med 7:5477-5483; 2014. [30] Tsikas, D.; Rode, I.; Becker, T.; Nashan, B.; Klempnauer, J.; Frolich, J. C. Elevated plasma and urine levels of ADMA and 15(S)-8-iso-PGF2alpha in end-stage liver disease. Hepatology 38:1063-1064; 2003.

[31] Dworski, R.; Roberts, L. J., 2nd; Murray, J. J.; Morrow, J. D.; Hartert, T. V.; Sheller, J. R. Assessment of oxidant stress in allergic asthma by measurement of the major urinary metabolite of F2-isoprostane, 15-F2t-IsoP (8-iso-PGF2alpha). Clin Exp Allergy 31:387-390; 2001.

[32] Aitken, R. J.; Smith, T. B.; Lord, T.; Kuczera, L.; Koppers, A. J.; Naumovski, N.; Connaughton, H.; Baker, M. A.; De Iuliis, G. N. On methods for the detection of reactive oxygen species generation by human spermatozoa: analysis of the cellular responses to catechol oestrogen, lipid aldehyde, menadione and arachidonic acid. Andrology 1:192-205; 2013.

[33] Munoz, P. M.; Ferrusola, C. O.; Lopez, L. A.; Del Petre, C.; Garcia, M. A.; de Paz Cabello, P.; Anel, L.; Pena, F. J. Caspase 3 Activity and Lipoperoxidative Status in Raw Semen Predict the Outcome of Cryopreservation of Stallion Spermatozoa. Biol Reprod 95:53; 2016.

[34] Martin Munoz, P.; Ortega Ferrusola, C.; Vizuete, G.; Plaza Davila, M.; Rodriguez Martinez, H.; Pena, F. J. Depletion of Intracellular Thiols and Increased Production of 4-Hydroxynonenal that Occur During Cryopreservation of Stallion Spermatozoa Lead to Caspase Activation, Loss of Motility, and Cell Death. Biol Reprod 93:143; 2015.

[35] Gibb, Z.; Lambourne, S. R.; Curry, B. J.; Hall, S. E.; Aitken, R. J. Aldehyde Dehydrogenase Plays a Pivotal Role in the Maintenance of Stallion Sperm Motility. Biol Reprod 94:133; 2016.

[36] Aitken, R. J.; Gibb, Z.; Mitchell, L. A.; Lambourne, S. R.; Connaughton, H. S.; De Iuliis, G. N. Sperm motility is lost in vitro as a consequence of mitochondrial free radical production and the generation of electrophilic aldehydes but can be significantly rescued by the presence of nucleophilic thiols. Biol Reprod 87:110; 2012.

[37] Aitken, R. J.; Wingate, J. K.; De Iuliis, G. N.; Koppers, A. J.; McLaughlin, E. A. Cis-unsaturated fatty acids stimulate reactive oxygen species generation and lipid peroxidation in human spermatozoa. J Clin Endocrinol Metab 91:4154-4163; 2006.

[38] Kumar, A.; Kingdon, E.; Norman, J. The isoprostane 8-iso-PGF2alpha suppresses monocyte adhesion to human microvascular endothelial cells via two independent mechanisms. FASEB J 19:443-445; 2005.

[39] Purdey, M. S.; Connaughton, H. S.; Whiting, S.; Schartner, E. P.; Monro, T. M.; Thompson, J. G.; Aitken, R. J.; Abell, A. D. Boronate probes for the detection of hydrogen peroxide release from human spermatozoa. Free Radic Biol Med 81:69-76; 2015.

[40] Aitken, R. J.; De Iuliis, G. N.; Gibb, Z.; Baker, M. A. The Simmet lecture: new horizons on an old landscape--oxidative stress, DNA damage and apoptosis in the male germ line. Reprod Domest Anim 47 Suppl 4:7-14; 2012. 
[41] Aitken, R. J.; Findlay, J. K.; Hutt, K. J.; Kerr, J. B. Apoptosis in the germ line. Reproduction 141:139-150; 2011.

[42] Aitken, R. J.; Koppers, A. J. Apoptosis and DNA damage in human spermatozoa. Asian J Androl 13:36-42; 2011.

[43] Ortega Ferrusola, C.; Gonzalez Fernandez, L.; Morrell, J. M.; Salazar Sandoval, C.; Macias Garcia, B.; Rodriguez-Martinez, H.; Tapia, J. A.; Pena, F. J. Lipid peroxidation, assessed with BODIPY-C11, increases after cryopreservation of stallion spermatozoa, is stallion-dependent and is related to apoptotic-like changes.

Reproduction 138:55-63; 2009.

[44] Criddle, D. N.; Gillies, S.; Baumgartner-Wilson, H. K.; Jaffar, M.; Chinje, E. C.; Passmore, S.; Chvanov, M.; Barrow, S.; Gerasimenko, O. V.; Tepikin, A. V.; Sutton, R.; Petersen, O. H. Menadione-induced reactive oxygen species generation via redox cycling promotes apoptosis of murine pancreatic acinar cells. J Biol Chem 281:4048540492; 2006.

[45] Ortega Ferrusola, C.; Gonzalez Fernandez, L.; Salazar Sandoval, C.; Macias Garcia, B.; Rodriguez Martinez, H.; Tapia, J. A.; Pena, F. J. Inhibition of the mitochondrial permeability transition pore reduces "apoptosis like" changes during cryopreservation of stallion spermatozoa. Theriogenology 74:458-465; 2010.

[46] Franco, R.; Cidlowski, J. A. Apoptosis and glutathione: beyond an antioxidant. Cell Death Differ 16:1303-1314; 2009.

[47] Liebeke, M.; Pother, D. C.; van Duy, N.; Albrecht, D.; Becher, D.; Hochgrafe, F.; Lalk, M.; Hecker, M.; Antelmann, H. Depletion of thiol-containing proteins in response to quinones in Bacillus subtilis. Mol Microbiol 69:1513-1529; 2008.

[48] Cho, Y. S.; Kim, M. J.; Lee, J. Y.; Chung, J. H. The role of thiols in protecting against simultaneous toxicity of menadione to platelet plasma and intracellular membranes. J Pharmacol Exp Ther 280:1335-1340; 1997.

[49] Miller, M. G.; Rodgers, A.; Cohen, G. M. Mechanisms of toxicity of naphthoquinones to isolated hepatocytes. Biochem Pharmacol 35:1177-1184; 1986. [50] Di Monte, D.; Bellomo, G.; Thor, H.; Nicotera, P.; Orrenius, S. Menadioneinduced cytotoxicity is associated with protein thiol oxidation and alteration in intracellular Ca2+ homeostasis. Arch Biochem Biophys 235:343-350; 1984.

[51] Di Monte, D.; Ross, D.; Bellomo, G.; Eklow, L.; Orrenius, S. Alterations in intracellular thiol homeostasis during the metabolism of menadione by isolated rat hepatocytes. Arch Biochem Biophys 235:334-342; 1984.

\section{FIGURE LEGENDS}

Figure 1.- Gating strategy and representative cytograms of the assay determining sperm viability, mitochondrial membrane potential and 8-iso-PGF $2 \alpha$. Stallion semen samples were stained as described in material and methods and analyzed using flow cytometry. A) Florescence minus one (FMO) controls for gating positivity for 8-iso-PGF P $_{2}$, only two populations of spermatozoa are present, live (L) and dead (D) spermatozoa. B) 8-iso$\mathrm{PGF}_{2 \alpha}$ in live and dead spermatozoa in control samples C) 8-iso-PGF $\mathrm{PF}_{2 \alpha}$ in $\mathrm{SO}_{4} \mathrm{Fe}$ treated samples. D) 8-iso-PGF 2 in menadione treated samples. E) Overlay histograms showing the effect of SO4Fe treatment in 8-iso-PGF $2 \alpha$ in stallion spermatozoa. F) Cytogram showing mitochondrial membrane potential in spermatozoa, L (low MMM) and H (High MMP). 
Figure 2.- Gating strategy and representative cytograms of the assay determining sperm viability, caspase 3 activity and 4-HNE in stallion spermatozoa. Semen samples were processed and stained as described in material and methods and analyzed using flow cytometry. A) Determination of viability, the combination of H33342 end ethidium homodimer, revealed three populations live dead and a population classified as ?, this population was further evaluated in $\mathrm{C}$ and corresponded to spermatozoa expressing caspase 3. B) Identification of caspase 3 activity in stallion spermatozoa C) Hierarchical gating of the populations detected in A, for the study of caspase 3 activity in each. D) Identification of 4-HNE. E) Representative histogram overlay showing increased expression of 4-HNE in the population of spermatozoa expressing caspase 3.

Figure 3.- Effect of menadione and $\mathrm{SO}_{4} \mathrm{Fe}$ in the generation of 8-iso- $\mathrm{PGF}_{2 \alpha}$ in stallion spermatozoa. Stallion ejaculates were processed as indicated in material and methods and 8-iso-PGF ${ }_{2 \alpha}$ was determined after 1 hour (A), $3(\mathrm{~B}), 6(\mathrm{C})$ and 9 hours of incubation at $37^{\circ} \mathrm{C}$ (D). Results represent means \pm SEM. ${ }^{* *} \mathrm{p}<0.01,{ }^{* * *} \mathrm{p}<0.001$

Figure 4- Effect of menadione and $\mathrm{SO}_{4} \mathrm{Fe}$ in the generation of 4-HNE in stallion spermatozoa. Semen samples were obtained and processed as indicated in material and methods and formation of 4-HNE measured in three different sperm subpopulations after 1 hour (A), 3 (B), 6 (C) and 9 (D) hours of incubation at $37^{\circ} \mathrm{C}$. Results are given as means \pm SEM. ${ }^{* *} \mathrm{p}<0.01, * * * \mathrm{p}<0.001$

Figure 5.- Effect of menadione and $\mathrm{SO}_{4} \mathrm{Fe}$ in sperm motility; changes in sperm motility were monitored after 1 hour (A), 3 (B) 6 (C) and 9 hours of incubation at $37^{\circ} \mathrm{C}$. E representative image of control samples, red lines depict trajectories of rapid motile, spermatozoa. F representative image of samples treated with menadione, all spermatozoa remained immotile. Results are given as means \pm SEM. ${ }^{* *} \mathrm{p}<0.01$, $* * * \mathrm{p}<0.001$

Figure 6.- Effects of Menadione and $\mathrm{SO}_{4} \mathrm{Fe}$ in stallion sperm viability. Changes after 1 hour (A), three hours (B), 6 hours (C) and 9 hours (D) of incubation at $37^{\circ} \mathrm{C}$. Viability is defined as the percentage of spermatozoa with intact membranes and negative for caspase 3. Results are given as means \pm SEM. ${ }^{* *} \mathrm{p}<0.01,{ }^{* * *} \mathrm{p}<0.001$

Figure 7.- Effects of Menadione and $\mathrm{SO}_{4} \mathrm{Fe}$ in the activation of caspase 3 in stallion spermatozoa incubated at $37^{\circ} \mathrm{C}$ after 1 hour (A), three (B), six (C) and nine hours of incubation (D). Results are given as means \pm SEM. ${ }^{* *} \mathrm{p}<0.01$

Figure 8.- Effects of Menadione and $\mathrm{SO}_{4} \mathrm{Fe}$ in necrotic sperm death in stallion spermatozoa. Stallion ejaculates were collected and processed as indicated in material and methods. Percentages of necrotic sperm were determined using flow cytometry after 1 hour (A), three (B), six (C) and nine hours of incubation (D). Results are given as means \pm SEM. ${ }^{* *} \mathrm{p}<0.01$

Figure 9.- Effects of Menadione and $\mathrm{SO}_{4} \mathrm{Fe}$ in the percentages of stallion spermatozoa showing high mitochondrial membrane potential. Stallion ejaculates were collected and examined as described in material and methods and the mitochondrial membrane potential analyzed using flow cytometry after 1 hour (A), three (B), six (C) and nine hours of incubation (D). Results are given as means \pm SEM. $* * \mathrm{p}<0.01$ 
Figure 10.- Effects of Menadione and $\mathrm{SO}_{4} \mathrm{Fe}$ in total thiol content in stallion spermatozoa incubated at $37^{\circ} \mathrm{C}$ after 1 hour (A), three (B), six (C) and nine hours of incubation (D). Results are given as means \pm SEM. ${ }^{* * *} \mathrm{p}<0.001$. 